\title{
Awareness, perceived risk and practices related to cervical cancer and Pap smear screening: A cross- sectional study among HIV-positive women attending an urban HIV clinic in Johannesburg, South Africa
}

\author{
I Mokhele, ${ }^{1}$ BSc, MSc; D Evans, ${ }^{2}$ DBiomed; K Schnippel,,${ }^{1,3}$ MPA; A Swarts, ${ }^{3}$ MSc; J S Smith, ${ }^{4}$ BA, MPH, PhD; \\ C Firnhaber, ${ }^{1,3} \mathrm{MD}$, MS, DTM\&H \\ ${ }^{1}$ Right to Care, Johannesburg, South Africa \\ ${ }^{2}$ Health Economics and Epidemiology Research Office, Department of Internal Medicine, Faculty of Health Sciences, University of the \\ Witwatersrand, Johannesburg, South Africa \\ ${ }^{3}$ Clinical HIV Research Unit, Department of Internal Medicine, Faculty of Health Sciences, University of the Witwatersrand, Johannesburg, \\ South Africa \\ ${ }^{4}$ Department of Epidemiology, Gillings School of Global Public Health, University of North Carolina-Chapel Hill, Chapel Hill, NC, USA
}

Corresponding author: I Mokhele (idah.mokhele@gmail.com)

\begin{abstract}
Background. Cervical cancer is a major cause of cancer-related deaths, especially in the context of the HIV epidemic. Objective. To examine awareness, perceived risk and practices related to cervical cancer screening among HIV-positive women. Methods. Interviewer-administered structured questionnaires were administered to HIV-positive women (aged $\geq 18$ years) enrolled in a cervical cancer screening study at the Themba Lethu Clinic, Johannesburg, South Africa, from November 2009 to December 2011. Modified Poisson regression with robust standard errors was used to identify factors at enrolment associated with awareness, perceived risk and adequate practice related to cervical screening. Adjusted relative risks (aRRs) with $95 \%$ confidence intervals (CIs) are presented. Results. Of the 1202 women enrolled, $71.3 \%$ and 18.2\% were aware of the Pap smear and HPV, respectively. Of the 1192 participants with data evaluated, $76.5 \%$ were worried and $23.5 \%$ were not worried about cervical cancer; $28.6 \%$ of the women had adequate screening practice. Older age ( 40 - 49 years or $\geq 50$ years v. 18 - 29 years) (aRR 1.63, 95\% CI 1.12 - 2.37; aRR 2.22, 95\% CI 1.44 - 3.41), higher education (tertiary v. less than grade 10) (aRR 1.39, 95\% CI 1.00 - 1.93), initiation on combination antiretroviral therapy (aRR 1.36, 95\% CI 1.00 - 1.85) and awareness of Pap smear screening (aRR 16.18, 95\% CI 7.69 - 34.01) were associated with adequate screening practice.

Conclusions. High levels of Pap smear awareness and low levels of Pap smear screening uptake were observed. However, Pap smear awareness was associated with adequate screening practice. More research into effective health education programmes to address these gaps is needed.
\end{abstract}

S Afr Med J 2016;106(12):1247-1253. DOI:10.7196/SAMJ.2016.v106i12.11224

Cervical cancer is the second most common cancer to affect women globally, with 527624 new cases and 265672 deaths from the disease annually. ${ }^{[1]}$ The age-standardised incidence rate was reported as $31.7 / 100000$ for South Africa (SA) in 2014. ${ }^{[1]}$ It has been shown previously that human papillomavirus (HPV) plays an important role in the development of precancerous lesions and their progression to cancer. ${ }^{[2]}$ In addition, development of cervical cancer has been found to be associated with an early sexual debut, multiple sexual partners, smoking, and extended use of oral contraceptives. ${ }^{[3]}$

The association between HIV and invasive cervical cancer (ICC) is complex, with several studies now demonstrating an increased risk of preinvasive cervical lesions among HIV-positive women. ${ }^{[2,4]}$ HIV-positive women with more advanced immunosuppression (CD4 count $<200$ cells $/ \mu \mathrm{L}$ ) seem to be particularly vulnerable to infection with persistence of the high-risk HPV types that can lead to cancer. ${ }^{[4]}$ Previous studies have found a significantly higher prevalence of HPV among HIV-positive women compared with HIV-negative women ( $87 \%$ v. $54 \%$ in Burkina Faso and $80 \%$ v. $50 \%$ in Zambia), and an increased prevalence of high-risk HPV types ( $71 \%$ v. $40 \%$ in Burkina Faso and $70 \%$ v. $35 \%$ in Zambia). ${ }^{[5,6]}$ SA has the highest burden of HIV globally, with an estimated 4 million women living with HIV. ${ }^{[7]}$ Because of the increased risk of acquiring HPV among women who are HIV-positive, after 2010 the national HIV treatment guidelines included specific guidance for cervical cancer screening. ${ }^{[8]}$

For a national approach to cervical cancer screening to work, women need to be aware of cervical cancer and the associated risk factors, as well as the screening and treatment services available to them. If they are not aware of the disease and associated risks, they will not seek timely screening or treatment services and are therefore at an increased risk of poor health outcomes. ${ }^{[9,10]}$

Screening behaviour and general health-seeking behaviour related to prevention services have not been widely studied among HIVpositive women in SA, especially in the area of perceived risk and prevention screening practice in the era of increased life expectancy due to combination antiretroviral therapy (cART). Many of the studies involving cervical cancer and HIV-positive women in southern Africa focus on clinical aspects related to both diseases, as opposed to behavioural aspects such as women's cervical cancer screening practice.

\section{Objective}

To examine awareness, perceived risk and practices related to cervical cancer screening among HIV-positive women in an urban HIV clinic in Johannesburg, SA. 


\section{Methods}

\section{Study site and participants}

In April 2005, the non-governmental organisation Right to Care, in partnership with the SA government, established a cervical cancer screening and treatment centre alongside the HIV care, management and treatment facility at Themba Lethu Clinic, situated in a tertiary hospital in Johannesburg. A cervical cancer screening study (Validation of Implementation of Cervical Cancer Screening Applications in HIV-seropositive Women, VICAR 1) evaluating visual inspection with acetic acid, a standard Pap smear and HPV detection was performed at this centre. A questionnaire was administered by study staff. The primary results have been published. ${ }^{[11]}$

HIV-positive women aged $18-65$ years who were eligible to participate, enrolled into the primary study (VICAR 1) from November 2009 to December 2011, not pregnant at the time of enrolment and signed an informed consent form were included.

\section{Cervical cancer screening guidelines}

The conventional Papanicolaou (Pap) smear for cervical cancer screening is used in the SA public health system. ${ }^{[12]}$

The guidelines for the management of HIV/AIDS released by the SA National Department of Health in 2010 ${ }^{[8]}$ (applicable to the women in the study) states that all HIV-positive women need cervical cancer screening on diagnosis of HIV. If this test is negative, they are then screened every 3 years, irrespective of prior initiation cART status. If results are abnormal, the guidelines recommend a repeat Pap smear or referral for further investigation or treatment. ${ }^{[8]}$

\section{Data sources}

In the primary study, participants answered an intervieweradministered structured questionnaire containing coded questions about their medical, social and sexual history. The questionnaire also included a section that examined awareness, perceived risk and practices concerning cervical cancer and cervical cancer screening. The interviews were administered by trained female interviewers in the local languages, as appropriate. After the interview, women were provided with an education session that included information regarding cervical cancer and cervical cancer screening and treatment.

We conducted a cross-sectional study of these data for our study. Our study made use of all data collected as at the end of December 2011, which included all 1202 study participants.

\section{Study definitions}

Self-reported alcohol use, smoking or taking snuff (fine-ground tobacco intended for consumption by being inhaled or sniffed into the nose) denoted current use. Frequency of smoking and taking snuff was categorised according to the number of times the woman took snuff or the number of cigarettes smoked daily $(<5$ or $\geq 5)$. Age at study enrolment was categorised as $18-29,30-39,40-49$ and $\geq 50$ years. We also analysed race (black or other than black, including white, Asian and mixed races), nationality (South African or non-South African), marital status (single, married or cohabitating, divorced or separated, or widowed), highest level of education completed (less than Grade 10, Grade 10 - 12, or tertiary education), and employment status (full time, part time, self-employed or not employed). Clinical characteristics analysed included CD4 count at study enrolment $(\leq 100$, $101-250$ and $>250$ cells $/ \mu \mathrm{L}$ ), cART status at study enrolment (on cART or not on cART), self-reported previous Pap smear history (yes or no), and results if applicable (negative, low-grade lesion, high-grade lesion or invasive cervical cancer, or unknown).

Awareness (a dichotomous variable) regarding Pap smear screening and HPV was assessed based on whether the woman reported knowing what a Pap smear test is and whether she had ever heard about HPV, respectively. Perceived risk was assessed based on whether the woman indicated that she was very worried, somewhat worried or not worried about getting cervical cancer. For the analysis, a dichotomous variable was created by combining very worried and somewhat worried about getting cervical cancer. Pap screening practice was based on self-reported screening history before enrolment in the study and assessed according to the number of Pap smears over the number of years since HIV diagnosis. This was then categorised as adequate or not adequate practice according to the national HIV treatment guidelines. ${ }^{[8]}$

\section{Measurement and analysis}

Descriptive statistics were used to summarise demographic and clinical characteristics at enrolment in the primary study (VICAR 1). Categorical variables were described by frequencies and percentages using tabulations. For continuous variables, medians and interquartile ranges (IQRs) were used where appropriate.

Modified Poisson regression with robust standard errors was used to estimate relative risk (RR) to identify predictors at study enrolment of awareness, perceived risk and practices related to cervical cancer and screening. ${ }^{[13]}$ Factors identified as significant in the univariate model (using $p<0.2$ ) and a priori variables of importance and potential confounders were included in the multivariate model. The adjusted relative risk (aRR) and 95\% confidence intervals (CIs) are reported. All statistical tests performed in the analysis excluded missing data. Study data were analysed using Stata version 11 (StataCorp, USA).

\section{Ethical considerations}

The primary study (VICAR 1) was approved by the University of the Witwatersrand's Human Research Ethics Committee (Medical) (HREC ref. no. M090516) and for secondary analysis by the Human Ethics Committee (Medicine) of the University of North Carolina (Human Research Ethics Committee ref. no. 09-1968). Ethical clearance for the analysis presented in this article was obtained from the University of the Witwatersrand in 2012 (HREC ref. no. M120310). To maintain confidentiality, all personal identifiers were removed from the data before analysis.

\section{Results}

A total of 1202 HIV-positive women were screened and then enrolled in the study. Further information on screening results is reported from the primary study (VICAR 1$){ }^{[11]}$ The median age at study enrolment was 38 years (IQR 32 - 43) (Table 1). Of the 1202 participants, $160(13.3 \%)$ were divorced/separated or widowed. The majority of the women $(n=834,69.4 \%)$ had Grade 10 - 12 education, and $113(9.4 \%)$ had tertiary education. A total of 125 women (10.4\%) reported currently drinking alcohol and 125 (10.4\%) reported taking snuff. A small number reported current smoking $(n=42,3.5 \%)$.

Almost all the women ( $n=1117,92.9 \%)$ were on cART at study enrolment (Table 2). The overall median CD4 count for the group was 394 cells/ $\mu \mathrm{L}$ (IQR 252 - 577) for the 1190 participants with data evaluated, based on their most recent CD4 level at study enrolment. The majority of the small number of study participants $(n=84,7.0 \%)$ who were not initiated on cART at study enrolment were not eligible for cART on the basis of their CD4 count and the HIV treatment guidelines at the time. ${ }^{[8]}$

\section{Previous Pap smear results}

A total of $57.2 \%$ of the women (688/1 202) self-reported a Pap smear screening history before the study, and $80.4 \%(553 / 688)$ of these 


\begin{tabular}{|c|c|}
\hline Variable & $n(\%)$ \\
\hline \multicolumn{2}{|l|}{ Age (yr) } \\
\hline Median (IQR) & $38(32-43)$ \\
\hline $18-29$ & $161(13.4)$ \\
\hline $30-39$ & $546(45.4)$ \\
\hline $40-49$ & $397(33.0)$ \\
\hline$\geq 50$ & $98(8.2)$ \\
\hline \multicolumn{2}{|l|}{ Race } \\
\hline Black & $1179(98.1)$ \\
\hline Other & $23(1.9)$ \\
\hline \multicolumn{2}{|l|}{ Nationality } \\
\hline South African & $1075(89.4)$ \\
\hline Non-South African & $112(9.3)$ \\
\hline Information missing & $15(1.3)$ \\
\hline \multicolumn{2}{|l|}{ Marital status } \\
\hline Single & $658(54.7)$ \\
\hline Married/cohabiting & $384(32.0)$ \\
\hline Divorced/separated/widowed & $160(13.3)$ \\
\hline \multicolumn{2}{|l|}{ Education } \\
\hline$<$ Grade 10 & $229(19.1)$ \\
\hline Grade $10-12$ & $834(69.4)$ \\
\hline Tertiary & $113(9.4)$ \\
\hline No education & $26(2.2)$ \\
\hline \multicolumn{2}{|l|}{ Employment } \\
\hline Full time & $448(37.3)$ \\
\hline Part time & $182(15.1)$ \\
\hline Self-employed & $26(2.2)$ \\
\hline Not employed & $523(43.5)$ \\
\hline Information missing & $23(1.9)$ \\
\hline \multicolumn{2}{|l|}{ Drinking alcohol } \\
\hline Yes & $125(10.4)$ \\
\hline No & $1077(89.6)$ \\
\hline \multicolumn{2}{|l|}{ Smoking } \\
\hline Yes & $42(3.5)$ \\
\hline$<5$ cigarettes/day & $28(66.7)$ \\
\hline$\geq 5$ cigarettes/day & $14(33.3)$ \\
\hline No & $1160(96.5)$ \\
\hline \multicolumn{2}{|l|}{ Taking snuff } \\
\hline Yes & $125(10.4)$ \\
\hline$<5$ times/day & $98(82.4)$ \\
\hline$\geq 5$ times/day & $21(17.7)$ \\
\hline No & $1077(89.6)$ \\
\hline
\end{tabular}

could recall their result. Of these, $94.6 \%(523 / 553)$ reported that their previous Pap smear results were negative, 5.2\% (29/553) reported low-grade Pap smear results, and $0.2 \%$ (1/553) reported high-grade Pap smear results.

\section{Awareness, perceived risk, and adequate practice}

A total of $71.3 \%$ of participants (857/1 202) were aware of Pap smear screening, and $18.2 \%(218 / 1201)$ were aware of HPV. A few women $(1.9 \%, 13 / 688)$ who reported having a previous Pap smear indicated they were not aware of the Pap smear screening test. Only $15.5 \%$ of participants (186/1 201) indicated awareness of both the Pap smear test and HPV (Fig. 1). A total of 1192 participants responded to the question about perceived risk related to cervical cancer. Of these, 912 $(76.5 \%)$ were worried or very worried about getting cervical cancer.
Table 2. Clinical characteristics of the study participants at enrolment $(N=1202)$

\begin{tabular}{ll}
\hline Variable & $\boldsymbol{n}(\%)$ \\
\hline $\mathrm{CD} 4$ count $(\mathrm{cells} / \mu \mathrm{L})$ at study enrolment & \\
Median $(\mathrm{IQR})$ & $394(252-572)$ \\
$0-100$ & $44(3.7)$ \\
$101-250$ & $249(20.7)$ \\
$>251$ & $897(74.6)$ \\
$\quad$ Information missing & $12(1.0)$ \\
On cART & $1117(92.9)$ \\
Yes & $84(7.0)$ \\
No & $1(0.1)$ \\
Information missing & \\
Previous Pap smear screening history & $688(57.2)$ \\
$\quad$ Yes & $514(42.8)$ \\
No & \\
Previous Pap smear results & $523(76.0)$ \\
Negative & $29(4.2)$ \\
Low grade & $1(0.1)$ \\
High grade/ICC & $135(19.6)$ \\
Information missing &
\end{tabular}

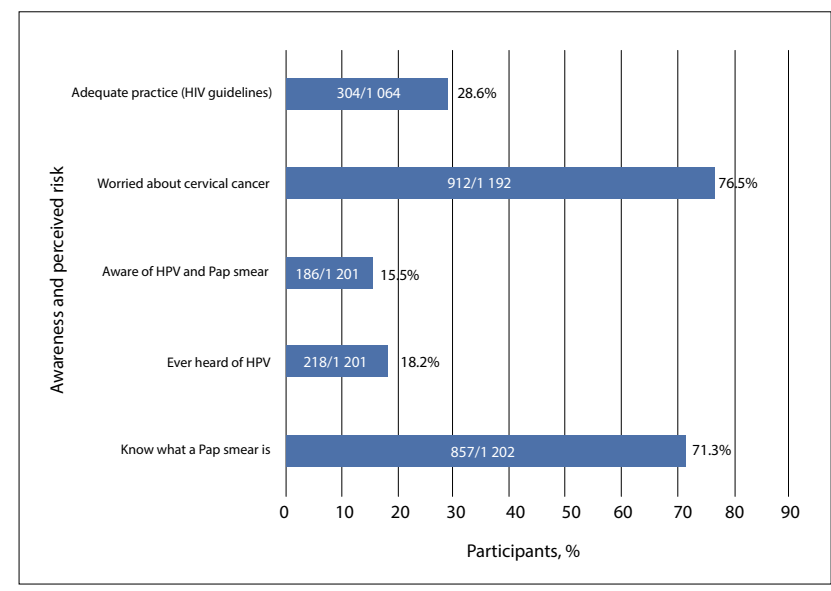

Fig. 1. Survey responses.

According to the national HIV treatment guidelines based on year of HIV diagnosis before the study, 28.6\% (304/1 064) had adequate cervical cancer screening practice.

\section{Factors associated with awareness and perceived risk}

Table 3 presents results of the analysis of association between sociodemographic and clinical characteristics and awareness related to Pap smear screening and HPV. Multivariate analysis indicated that older women (aged 40 - 49 years or $\geq 50$ years v. 18 - 29 years) (aRR 1.14, 95\% CI 1.00 - 1.30; aRR 1.29, 95\% CI 1.09 - 1.52) and those with a higher level of education (Grade $10-12$ or tertiary v. less than Grade 10) (aRR 1.26, 95\% CI 1.12 - 1.42; aRR 1.35, 95\% CI 1.16 1.56) were more likely than other women in the study to be aware of Pap smear screening. Non-South Africans (aRR 0.86, 95\% CI 0.74 $1.00)$ and women who did not have a previous history of Pap smear screening (aRR $0.36,95 \%$ CI 0.32 - 0.41) were less likely than other women in the study to be aware of Pap smear screening. The other covariates were not found to be statistically associated with awareness of Pap smear screening (Table 3).

Women with a higher level of education (Grade $10-12$ or tertiary v. less than Grade 10) (aRR 2.56, 95\% CI 1.57 - 4.15; aRR 2.97, 95\% 


\begin{tabular}{|c|c|c|}
\hline Factor & $\begin{array}{l}\text { Pap awareness, } \\
\text { aRR }(95 \% \mathrm{CI})^{\dagger}\end{array}$ & $\begin{array}{l}\text { HPV awareness, } \\
\text { aRR }(95 \% \mathrm{CI})^{\ddagger}\end{array}$ \\
\hline \multicolumn{3}{|l|}{ Age (yr) } \\
\hline $18-29$ & Ref & Ref \\
\hline $30-39$ & $1.11(0.98-1.25)$ & $1.32(0.88-1.97)$ \\
\hline $40-49$ & $1.14(1.00-1.30)^{*}$ & $1.37(0.90-2.08)$ \\
\hline$\geq 50$ & $1.29(1.09-1.52)^{\star}$ & $0.82(0.41-1.63)$ \\
\hline \multicolumn{3}{|l|}{ Race } \\
\hline Black & Ref & - \\
\hline Other & $1.03(0.91-1.16)$ & - \\
\hline \multicolumn{3}{|l|}{ Nationality } \\
\hline South African & Ref & - \\
\hline Non-South African & $0.86(0.74-1.00)^{\star}$ & - \\
\hline \multicolumn{3}{|l|}{ Marital status } \\
\hline Single & Ref & - \\
\hline Married/cohabiting & $0.99(0.90-1.06)$ & - \\
\hline Divorced/separated/widowed & $1.05(0.95-1.17)$ & - \\
\hline \multicolumn{3}{|l|}{ Education } \\
\hline$<$ Grade 10 & Ref & Ref \\
\hline Grade $10-12$ & $1.26(1.12-1.42)^{*}$ & $2.56(1.57-4.15)^{\star}$ \\
\hline Tertiary & $1.35(1.16-1.56)^{\star}$ & $2.97(1.67-5.30)^{*}$ \\
\hline No education & $0.92(0.65-1.31)$ & $0.53(0.07-3.89)$ \\
\hline \multicolumn{3}{|l|}{ Employment } \\
\hline Full time & Ref & Ref \\
\hline Part time & - & $1.15(0.80-1.68)$ \\
\hline Self-employed & - & $1.60(0.88-2.91)$ \\
\hline Not employed & - & $1.16(0.89-1.53)$ \\
\hline \multicolumn{3}{|l|}{ Drinking alcohol } \\
\hline Yes & Ref & Ref \\
\hline No & $0.98(0.78-1.45)$ & $0.73(0.53-1.01)$ \\
\hline \multicolumn{3}{|l|}{ Taking snuff } \\
\hline Yes & Ref & - \\
\hline No & $1.41(0.99-1.09)$ & - \\
\hline \multicolumn{3}{|l|}{ On cART } \\
\hline Yes & Ref & - \\
\hline No & $1.10(0.98-1.25)$ & - \\
\hline \multicolumn{3}{|l|}{ Previous Pap screening history } \\
\hline Yes & Ref & Ref \\
\hline No & $0.36(0.32-0.41)^{\star}$ & $0.71(0.55-0.92)^{\star}$ \\
\hline
\end{tabular}

CI 1.67 - 5.30) were more likely than other women in the study to be aware of HPV. Women who did not have a previous history of Pap smear screening (aRR 0.71, 95\% CI 0.55 - 0.92) were less likely than other women in the study to be aware of HPV. The other covariates were not found to be statistically associated with awareness of HPV (Table 3).

Table 4 presents results of the analysis of association between sociodemographic and clinical characteristics and being at risk of cervical cancer and practice related to Pap smear screening. Women with a higher level of education (Grade 10 - 12 or tertiary v. less than Grade 10) (aRR 1.10, 95\% CI 1.01 - 1.20; aRR 1.16, 95\% CI 1.03 1.31 ) and those who did not take snuff (aRR 1.14, 95\% CI 1.00 - 1.29) were more likely than other women in the study to be worried about cervical cancer. Women who reported a history of alcohol use (aRR $0.89,95 \%$ CI $0.82-0.97$ ) were less likely than other women in the study to be worried about cervical cancer. The other covariates were not found to be statistically associated with practice related to Pap smear screening (Table 4).

Older women (aged 40 - 49 or $\geq 50$ years v. 18 - 29 years) (aRR 1.63, 95\% CI 1.12 - 2.37; aRR 2.22, 95\% CI 1.44 - 3.41), those with a higher education (tertiary v. less than Grade 10) (aRR 1.39, 95\% CI 1.00 1.93) and those initiated on cART (aRR 1.36, 95\% CI 1.00 - 1.85) were more likely than other women in the study to have adequate Pap smear screening practice according to the HIV treatment guidelines.

\section{Association between awareness and perceived risk and adequate practice}

Table 5 presents the results of the analysis examining the association between awareness, perceived risks and adequate screening practice 
Table 4. Factors associated with Pap smear screening practice and perceived risk

\begin{tabular}{|c|c|c|}
\hline Factor & $\begin{array}{l}\text { Perceived risk, } \\
\operatorname{aRR}(95 \% \mathrm{CI})^{\dagger}\end{array}$ & $\begin{array}{l}\text { Practice according } \\
\text { to HIV treatment } \\
\text { guidelines, } \\
\text { aRR }(95 \% \mathrm{CI})^{\ddagger}\end{array}$ \\
\hline \multicolumn{3}{|l|}{ Age (yr) } \\
\hline $18-29$ & Ref & Ref \\
\hline $30-39$ & $1.18(0.72-1.93)$ & $1.33(0.92-1.92)$ \\
\hline $40-49$ & $1.01(0.61-1.69)$ & $1.63(1.12-2.37)^{*}$ \\
\hline$\geq 50$ & $1.09(0.60-2.00)$ & $2.22(1.44-3.41)^{\star}$ \\
\hline \multicolumn{3}{|l|}{ Race } \\
\hline Black & - & Ref \\
\hline Other & - & $1.31(0.85-2.02)$ \\
\hline \multicolumn{3}{|l|}{ Education } \\
\hline$<$ Grade 10 & Ref & Ref \\
\hline Grade $10-12$ & $1.10(1.01-1.20)^{\star}$ & $0.85(0.66-1.08)$ \\
\hline Tertiary & $1.16(1.03-1.31)^{\star}$ & $1.39(1.00-1.93)^{*}$ \\
\hline No education & $0.88(0.64-1.22)$ & $0.77(0.39-1.52)$ \\
\hline \multicolumn{3}{|l|}{ Employment } \\
\hline Full time & Ref & Ref \\
\hline Part time & $1.06(0.81-1.71)$ & $0.78(0.58-1.06)$ \\
\hline Self-employed & $1.20(1.03-1.39)$ & $1.30(0.76-2.23)$ \\
\hline Not employed & $1.09(1.01-1.17)$ & $0.92(0.75-1.14)$ \\
\hline \multicolumn{3}{|l|}{ Drinking alcohol } \\
\hline Yes & Ref & Ref \\
\hline No & $0.89(0.82-0.97)^{\star}$ & $0.98(0.76-1.27)$ \\
\hline \multicolumn{3}{|l|}{ Taking snuff } \\
\hline Yes & Ref & Ref \\
\hline No & $1.14(1.00-1.29)^{\star}$ & $1.28(0.93-1.76)$ \\
\hline \multicolumn{3}{|l|}{ On cART } \\
\hline Yes & - & Ref \\
\hline No & - & $1.36(1.00-1.85)^{\star}$ \\
\hline \multicolumn{3}{|c|}{$\begin{array}{l}\text { Ref }=1.00 ;-=\text { not included in the multivariate analysis, not significant in the univariate } \\
\text { analysis. } \\
{ }^{*} \text { Statistically significant }(p<0.005) \text {. } \\
\text { "Adjusted for age, education, employment, alcohol use and snuff use. } \\
\text { *Adjusted for age, education, employment, alcohol use, snuff use and cART. }\end{array}$} \\
\hline
\end{tabular}

according to the HIV treatment guidelines. Crude and aRR results are reported. Models were adjusted for age, education level, and prior initiation on cART.

Multivariate analysis indicated that awareness of Pap smear screening was associated with adequate screening practice (aRR 16.18, 95\% CI $7.69-34.01$ ) according to the HIV treatment guidelines. However, awareness of HPV and perception of being at risk of cervical cancer were not significantly associated with adequate screening practice.

\section{Discussion}

\section{Pap smear screening and HPV awareness}

Results from our study showed that most (71.3\%) HIV-positive women in care at a public sector HIV clinic in urban Johannesburg reported being aware of Pap smear screening. A study conducted among much younger (mean age 22 years) tertiary students in the Eastern Cape Province of SA showed similar results, with $70 \%$ awareness of Pap smear screening among the study participants. ${ }^{[14]}$

Higher education was a common significant factor in all outcomes assessed in our study. Low literacy/education has been shown to correlate with negative health behaviour and a higher risk of morbidity and mortality. ${ }^{[10,15]}$

Our results also showed that older women were more likely to be aware of Pap smear screening and to have adequate cervical cancer screening practice according to the HIV treatment guidelines. Cervical cancer has traditionally been a disease that mostly affects older women, and this age group would have been targeted with health education and screening services as part of the national screening programme. ${ }^{[10,12]}$

Our study participants were found to have low levels of HPV awareness, further highlighting the urgent need for effective health education programmes. Our study was conducted before the HPV vaccination programme was initiated in SA. The national HPV vaccination programme the country now has may result in wider awareness and knowledge regarding HPV in the country. This could be through media coverage of the vaccine programme, or women with daughters having access to information when interacting with the programme. ${ }^{[16]}$

Table 5. Impact of awareness and perceived risk on practice

\begin{tabular}{|c|c|c|c|c|}
\hline Factor & $\begin{array}{l}\text { Not adequate } \\
\text { practice, } \\
n(\%)\end{array}$ & $\begin{array}{l}\text { Adequate } \\
\text { practice, } \\
n(\%)\end{array}$ & RR $(95 \% \mathrm{CI})$ & $\operatorname{aRR}(95 \% \mathrm{CI})^{\dagger}$ \\
\hline \multicolumn{5}{|c|}{$\begin{array}{l}\text { Awareness of Pap smears } \\
(n=1063)\end{array}$} \\
\hline Not aware & $288(37.9)$ & $7(2.3)$ & Ref & Ref \\
\hline Aware & $471(62.1)$ & $297(97.7)$ & $16.27(7.78-34.04)^{*}$ & $16.18(7.69-34.01)^{*}$ \\
\hline \multicolumn{5}{|c|}{$\begin{array}{l}\text { Awareness of HPV } \\
(n=1062)\end{array}$} \\
\hline Not aware & $622(82.1)$ & $252(82.9)$ & Ref & Ref \\
\hline Aware & $136(17.9)$ & $52(17.1)$ & $0.96(0.75-1.23)$ & $0.99(0.77-1.27)$ \\
\hline \multicolumn{5}{|l|}{$\begin{array}{l}\text { Perceived risk } \\
(n=1053)\end{array}$} \\
\hline Not worried & $179(23.8)$ & $73(24.1)$ & Ref & Ref \\
\hline Worried & $572(76.2)$ & $230(75.9)$ & $0.99(0.79-1.24)$ & $1.00(0.81-1.25)$ \\
\hline
\end{tabular}




\section{Perceived risk related to cervical cancer and Pap screening}

Previous studies found that women's perceived risk may negatively influence screening behaviours and lead to an increased risk of morbidity and mortality. ${ }^{[10,17]}$ Women may believe that they are not susceptible to the disease, which may lead them to forgo screening, thereby missing out on the chance to have the disease detected and treated appropriately. Lack of awareness and knowledge about the disease and its prevention is seen as an important factor influencing women's perceptions regarding their risk related to the disease. ${ }^{[10,17]}$

Our study found that a majority (76.5\%) of the participants were worried about getting cervical cancer. Not taking snuff was one of the factors found to increase the likelihood of study participants being more worried about cervical cancer. Snuff use, a culturally relevant practice in our study setting, is a factor that has not been explored extensively in relation to cervical cancer. Nonetheless, it is a risky negative behaviour that may negatively influence health outcomes. Women who did not use snuff could therefore be expected to be more worried about cervical cancer than other women in the study, as their non-snuff-taking behaviour may indicate concern about negative health behaviour and outcomes. Alcohol use was found to decrease the likelihood of being worried about cervical cancer. Alcohol consumption is known to adversely influence both healthrelated behaviour and health outcomes, but levels of alcohol use were not quantified in the study, and this result should therefore be interpreted with caution. ${ }^{[18]}$

\section{Practices related to Pap smear screening}

In addition to older women and those with tertiary education, women on CART were found to be more likely than other women in the study to have adequate cervical cancer screening practice. Women on cART have probably been provided with health education and Pap smear screening through their encounters with the healthcare system during the course of their care and treatment, as recommended in the HIV guidelines.

\section{Study limitations}

This study has similar limitations to others that have included patient questionnaires about sexual and substance abuse history. Some individuals may have been too embarrassed to answer study questions of a personal nature truthfully. Information bias was minimised by using trained interviewers, having a standard operating procedure for conducting interviews, and using interviewers fluent in the local languages who could interview participants in their own language.

Selection bias may exist, as participants could have enrolled in the study because they were unwell (lower CD4 cell count), because their healthcare provider was particularly worried about their exposure to HPV, or because they were worried about cervical cancer and therefore willing to participate in a screening study. Since they were seeking HIV care and cART, these patients may be healthier than their HIV-positive counterparts who were eligible for cART but not in HIV care, or on CART and not seeking further care and treatment. Generalisability of our findings to populations at the non-tertiary, smaller or rural facilities found throughout SA may be limited, as Themba Lethu Clinic is an urban HIV treatment site situated in a tertiary hospital.

\section{Conclusions}

An important finding was that if participants were aware of Pap smear screening they were more likely to have adequate screening practice. However, despite high levels of Pap smear screening awareness, low screening uptake was noted among our study participants. Examining health education programmes related to cervical cancer could provide an opportunity to effectively address gaps in knowledge and awareness in order to improve screening practice.

Acknowledgements. The primary study (VICAR 1) was funded through the United States Agency for International Development (USAID), PEPFAR (674-A-00-08-00007-00), PHE ZA.09.0265, and the University of North Carolina Centre for AIDS Research (P30-AI50410). DE was funded by USAID under the terms of agreement USAID-674-A-12-00029 to the Health Economics and Epidemiology Research Office, and KS, CF and IM were funded through USAID 674-A-12-0002 to Right to Care. The funders had no role in study design, data collection and analysis, decision to publish, or preparation of the article. This study was made possible by the generous support of the American people through USAID. The contents are the responsibility of the authors and do not necessarily reflect the views of USAID or the US government.

Author contributions. IM conceptualised the study, conducted data analysis, interpreted the results and wrote the manuscript. DE and CF participated in conceptualisation, interpretation of results, and critical review of the manuscript. JSS, CF and AS designed the questionnaire for the primary study (VICAR 1). KS participated in drafting of the manuscript and analysis, and provided critical review of the manuscript. AS managed all data related to the primary study (VICAR 1) and participated in conceptualisation of the study. All authors read and approved the final draft of the manuscript.

Competing interests. JSS has received research grants and/or served on paid advisory boards for Hologic, BD Diagnostics, Trovagene and QIAGEN over the past 5 years. All the other authors have declared that they have no competing interests.

1. Bruni L, Barrionuevo-Rosas L, Albero G, et al. Human Papillomavirus and Related Diseases in the World. Summary Report 2016. Institut Català d'Oncologia Information Centre on HPV and Cancers, 2016. http://www.hpvcentre.net/statistics/reports/XWX.pdf (accessed 8 November 2016).

2. De Vuyst H, Ndirangu G, Moodley M, et al. Prevalence of human papillomavirus in women with invasive cervical carcinoma by HIV status in Kenya and South Africa. Int J Cancer 2012;131(4):949955. http://dx.doi.org/10.1002/ijc.26470

3. Green J, Berrington de Gonzalez A, Sweetland S, et al. Risk factors for adenocarcinoma and squamous cell carcinoma of the cervix in women aged 20-44 years: The UK National Case-Control Study of Cervical Cancer. Br J Cancer 2003;89(11):2078-2086. http://dx.doi.org/10.1038/sj.bjc.6601296

4. Firnhaber CS, van Le H, Pettifor A, et al. Association between cervical dysplasia and human 4. Firnhaber CS, van Le H, Pettifor A, et al. Association between cervical dysplasia and human
papillomavirus in HIV seropositive women from Johannesburg South Africa. Cancer Causes Control papillomavirus in HIV seropositive women from Johannesburg So

5. Didelot-Rousseau M-N, Nagot N, Costes-Martineau V, et al. Human papillomavirus genotype . Didelot-Rousseau $\mathrm{M}-\mathrm{N}$, Nagot $\mathrm{N}$, Costes-Martineau $\mathrm{V}$, et al. Human papillomavirus genotype
distribution and cervical squamous intraepithelial lesions among high-risk women with and distribution and cervical squamous intraepithelial lesions among high-risk women with and
without HIV-1 infection in Burkina Faso. Br J Cancer 2006;95(3):355-362. http://dx.doi.org/10.1038/ without HIV-1 infection in Burkina Faso. Br J Cancer 2006;95(3):355-362. http://dx.doi.org/10.1038/
s.bjc.6603252 s..bjc. 6603252 6. Ngandwe C, Lowe JJ, Richards PJ, et al. The distribution of sexually-transmitted human
papillomaviruses in HIV positive and negative patients in Zambia, Africa. BMC Infect Dis 2007;7:77. http://dx.doi.org/10.1186/1471-2334-7-77

7. UNAIDS. South Africa: HIV and AIDS estimates 2015. http://www.unaids.org/en/regionscountries/ countries/southafrica/ (accessed 8 November 2016)

8. National Department of Health, South Africa. Clinical Guidelines for the Management of HIV and AIDS in Adults and Adolescents 2010. http://www.who.int/hiv/pub/guidelines/south_africa_art.pdf (accessed 10 June 2014).

9. Janz NK, Becker MH. The Health Belief Model: A decade later. Health Educ Q 1984;11(1):1-47. http:// dx.doi.org/10.1177/109019818401100101

10. Wong LP, Wong YL, Low WY, Khoo EM, Shuib R. Knowledge and awareness of cervical cancer and Wong LP, Wong YL, Low WY, Khoo EM, Shuib R. Knowledge and awareness of cervical cancer and
screening among Malaysian women who have never had a Pap smear: A qualitative study. Singapore screening among Malaysian women who have never had a Pap smear: A qualitative study. Singapore
Med J 2009;50(1):49-53. http://www.ncbi.nlm.nih.gov/pubmed/19224084 (accessed 7 November Med J 2009;50(1):49-53. http://www.ncbi.nlm.nih.gov/pubmed/19224084 (accessed 7 November 2016)

11. Firnhaber C, Mayisela N, Mao L, et al. Validation of cervical cancer screening methods in HIV positive women from Johannesburg South Africa. PLoS One 2013;8:e53494. http://dx.doi.org/10.1371/journal. pone.0053494

12. National Department of Health, South Africa. National Guidelines for Cervical Cancer Screening Programme 2002. http://screening.iarc.fr/doc/SAcervical-cancer.pdf (accessed 10 June 2014).

13. Zou G. A modified poisson regression approach to prospective studies with binary data. Am J Epidemiol 2004;159(7):702-706. http://dx.doi.org/10.1093/aje/kwh090

14. Chikandiwa A, van Wyk BE. Knowledge and awareness of human papillomavirus and intention with regard to human papillomavirus vaccine uptake by female tertiary students in the Eastern Cape Province. S Afr J Epidemiol Infect 2013;28(4):215-220. http://www.sajei.co.za/index.php/SAIEI/article/ view/545/756 (accessed 7 November 2015).

15. Lindau ST, Basu A, Leitsch SA. Health literacy as a predictor of follow-up after an abnormal Pap smear: A prospective study. J Gen Intern Med 2006;21(8):829-834. http://dx.doi.org/10.1111/j.15251497.2006.00534.x 
16. Massad LS, Evans CT, Weber KM, et al. Changes in knowledge of cervical cancer following introduction of human papillomavirus vaccine among women at high risk for cervical cancer. Gynecol Oncol Rep 2015;12:37-40. http://dx.doi.org/10.1016/j.gore.2015.02.007

17. Were E, Nyaberi Z, Buziba N. Perceptions of risk and barriers to cervical cancer screening at Moi Teaching and Referral Hospital (MTRH), Eldoret, Kenya. Afr Health Sci 2011;11(1):58-64.
18. World Health Organization. Global status report on alcohol and health 2014. http://www.who.int/ substance_abuse/publications/global_alcohol_report/en/(accessed 8 November 2016).

Accepted 2 August 2016. 